\title{
Indigenous People and Research Collaboration: A Journey Across Cultural and Disciplinary Bounds
}

\author{
Heron Loban
}

Susan Ciccotosto

Josephine Pryce

Taha Chaiechi

James Cook University, Cairns

\begin{abstract}
This paper builds on an earlier paper by the authors that looked at the experiences of the authors as researchers in an interdisciplinary team. Expanding on this previous reflection, the researchers consider the concepts of an intercultural team and the role of Indigeniety in their research efforts. This paper looks at the experiences of the Indigenous and non-Indigenous researchers in a social capital framework. In the earlier paper the authors explored research at the disciplinary boundaries. With backgrounds in law, accounting, economics and human resources the ability to make connections and to have fruitful interactions at the borders to produce research outputs was, at the beginning, unknown by the team. Here, the authors explore research at the boundaries of Indigenous and non-Indigenous interactions and how the team members experienced the publication-writing process as a team of Indigenous and non-Indigenous researchers on an Indigenous research topic and finding that social capital may be the key for success.
\end{abstract}

\section{Introduction}

$\mathrm{T}$ his paper gives some insight into the publication-writing process of an intercultural, multidisciplinary group utilising the reflections of a small intra-campus group at a small regional university campus. The term 'publication-writing' is used because this was the end goal. Whilst the first publication-writing effort, upon which this paper is based, was unsuccessful, the team enjoyed later success after that initial paper was submitted and rejected. Over the past two years the team has presented three conference papers, two of which have been published and the other has been accepted for publication. The team has also received a small internal faculty grant and published an article in a national Indigenous journal. Such successes, by the team's standards, are real achievements. However, the reasons for the success remain somewhat unknown, even to the team members themselves. The earlier paper and this paper endeavour to find the reasons for the continued success and positive relationships this intercultural, interdisciplinary team enjoys. It is posed that the answer lies in social capital. To this end, the paper begins with a discussion of the meanings 
of interdisciplinary and intercultural research, followed by an explanation of social capital. The Indigenous topic which formed the basis of the initial publication-writing exercise will then be introduced and discussed together with some impacts for the development of Indigenous and non-Indigenous, interdisciplinary research groups. The paper will end with some concluding remarks, including some suggestions for further research and reflections.

\section{Interdisciplinary Research}

The meaning of interdisciplinary has been described in several ways in the literature. Strober (2011) viewed disciplines to exist when a university has a department specifically named or a major in a degree which encompasses the body of knowledge covered by the discipline. Interdisciplinary teams require knowledge be transferred between members of the team so that new knowledge can be created. Bordons (1999) considered interdisciplinarity to be defined as the collaboration between researchers from different fields.

Palmer and Neumann (2002) noted that at an individual level many researchers read widely, moving beyond what may be considered to be specific to their own discipline. These individuals showed an interest in the boundaries of their own discipline, such as researchers in accounting who considered social theories to explain the production of accounting numbers, or researchers in tourism who considered psychological motivation to tourist behaviour. Researchers who explored beyond their discipline built networks to enable knowledge transfer to overcome a lack of knowledge.

Haythornthwaite's (2006) research argued that effective knowledge transfer was required when interdisciplinary work occurred between the members of a team and concentrated on how this occurred. In line with this rationale, an interdisciplinary team is one in which knowledge transfer takes place to enable research outcomes that may differ from those of a single discipline. To enable interdisciplinary research, knowledge transfer which overcomes different ontologies and epistemologies requires an openness to change (Strober, 2011). Such openness is built upon trust between individuals.

\section{Intercultural Research}

Research collaboration, and in particular, interdisciplinary research as a way of doing research is being increasingly prioritised and valued by universities across Australia. Intercultural research, on the other hand, has received less attention. The importance of the cultural environment of universities however should not be underestimated. Manathunga (2009 p. 169) noted the many cultural environments academics work in, including ethnic, disciplinary, workplace and professional cultures that can impact on collaborative research efforts.

Manathunga (2009) conceptualised research in the contact zone and at the borders in a postcolonial context. Furthermore, Manathunga (2009) emphasised the importance of difference as a source of productivity and the value of cultural exchange in the research process and product. Other writers have expressed this scenario more specifically as the 'intercultural' aspect of collaborative research. Somerville and Perkins (2003) similarly referred to working in the 'contact zone' and at the 'borders'. From their viewpoint, research collaboration required both the Indigenous and non-Indigenous researchers to recognise their work existed in a contact zone and the researchers will in the course of the work cross borders. In particular, the researchers interviewed as part of their reflection on the research, underlined 
the discomfort felt when negotiating in the contact zone to make the research collaboration work and to allow the research to be done. For a number of the researchers, relationships prior to the research project were minimal. In some cases the researchers had not met each other before. This is in contrast to the work of the team the subject of this paper. The question is - does having prior relationships facilitate the research collaboration? This paper says 'yes' because of social capital.

\section{Social Capital}

Social capital facilitates a network's capacity and capabilities for creating, sharing and accessing knowledge (Nahapiet and Ghoshal, 1998). Organisations are social communities (communities of practice) which derive distinctive advantage by using social networks too quickly and efficiently access and transfer knowledge that exists within the community, using it to create new knowledge. Grounded in this notion of social capital is the focus on the importance of relationships and ties that form the basis for social interaction (Bourdieu, 1986; Baker, 1990; Nahapiet and Ghoshal, 1998). The crux of social capital theory is that it is these network ties and relationships which provide valuable resources to members in an efficient and cost effective manner, leading to benefits in forms of access, timing and referrals of information (Burt, 1992). Social capital highlights the importance of strong personal relationships developed over a period time. These personal relationships form the basis for goodwill, trust, cooperation and collective action in organisations. They allow people to contribute to the community of practice with an expectation that they too will benefit in some form in future through knowledge diffusion and transfer (Wenger, et al. 2002).

Trust has been expressed as a key by-product of social capital. As social capital builds so too can trust (Fattore et al, 2003). It is this trust that appears to be one of the strong features of the success of this team - trust built on social capital and trust that continues to grow with repeated positive social interactions.

The way in which social capital has been considered in respect of Indigenous people has taken a number of forms including with respect to both Indigenous communities and Indigenous individuals (Foley and O’Connor, 2013). Morrissey (2006) referred to the value of social capital for Indigenous people and communities. In particular, he contended that although a high level of social capital may exist within an Indigenous community amongst its members, it is not until social capital is built outside of that community, with non-Indigenous people and communities that such social capital will translate into other forms of capital such as financial capital (Morrissey, 2006 p. 241). Morrissey (2006, p. 241) summarised well the view of Naryan and Cassidy (2001) that at its core 'An intrinsic characteristic of social capital is that it is relational. ... [S]imply, social capital exists only when it is shared' (2001 p. 59). This leads into the formation of the team and the relationships between members.

\section{The Formation of the Intercultural Interdisciplinary Team}

The implications of relationship for intercultural, interdisciplinary collaborations which involve both Indigenous and non-indigenous are twofold. There is the relationship between the Indigenous and non-Indigenous researchers which has a cultural dimension. Then there is the relationship of the researchers, both Indigenous and non-Indigenous, to the research itself which impacts on Indigenous people either directly as Indigenous researchers or indirectly as the subjects of the research. 
When the conversations began about writing a paper together on the topic of Torres Strait commercial fisheries it was an attempt by two of the group members, one Indigenous and one non-Indigenous, to explore their seemingly polarised views on the topic. The group expanded as part of an 'experiment' of sorts to attempt to increase research outputs for each of the group members. And so, two colleagues became four with a common goal to submit a paper for publication. Publication-writing was to be the 'experiment'.

From the outset, social capital was present but it existed to varying levels between the team members. The team member from law had a reasonable amount of social capital with the team member from business whose background was in commercial fishing, and a small amount of social capital with the other two team members. The three team members from business had a solid amount of social capital between them as members of the same school though this was limited too as each was from a different discipline.

This was the starting point.

\section{The Phenomena: The Torres Strait Fishing Zone}

Both voluntary agreements and a fish management scheme exist in the Torres Strait in an endeavour to limit the fishing effort and provide for equitable shares for fishers, however there is continuing tension between the inherited rights of Indigenous fishers and the commercial fishers (English, 2001). Indigenous people living on the islands of the Torres Strait place great importance on their traditional way of life and livelihood (English, 2001). Commercial fishers also have a connection with fishing as an activity and a way of life which transcends the 'commercial', with the concept of profit as its chief aim.

The case of $R v$ Nona and Gesa brought to the fore the issues of fishing rights in the Torres Strait, though not in the context of native title or sea rights as one might expect, but rather in a criminal case involving the prosecution of two Torres Strait islander men in the District Court of Queensland. This case brought sharply into focus the nature and depth of the conflict between Torres Strait Islander fishers and non-Indigenous commercial fishers fishing in the waters of the Torres Strait. On 6 May 1998 the dinghy of a mother ship was fishing in the waters outside of Mer (Murray Island) in the eastern part of the Torres Strait. Whilst there, the commercial fishers in the dinghy were met by Nona and Gesa and another Torres Strait Islander from Mer in a dinghy. Nona and Gesa contended that the commercial fishers were within an exclusive economic zone which was the subject of a 'gentleman's agreement' between the Torres Strait Islander people of that area and commercial fishers. And, that by being within that zone the commercial fishers were in breach of that gentleman's agreement. The Torres Strait Islanders took from the commercial fishers a quantity of fish. The Torres Strait Islanders were charged with armed robbery (they were holding fishing spears) and were found not guilty.

After the case, Indigenous people demanded that all non-Indigenous commercial fishers leave the area by the $31^{\text {st }}$ March 2001. There were threats of violence and talk of "war". This case highlights the conflict between Indigenous people who see the fishing of their traditional waters as a native right and the commercial fishers who also view fishing as part of their identity and tradition, exhibiting an emotional and existential attachment to their job (English,

\footnotetext{
${ }^{1}$ A gentleman's agreement is an agreement which relies on the good faith of the parties for adherence. It is not a contract which is legally binding and enforceable in a court of law in Australia.
} 
2001, Shaw, 2008). This remains an ongoing issue with public meetings about the conflict being held as recently as June 2013 on Thursday Island (Smith, 2013, p. 1).

This topic of commercial fisheries in the Torres Strait was considered appropriate for our publication writing 'experiment' because members of the team had access to the Islander commercial fishers, non-Islander commercial fishers and a member of the legal profession who has represented both sides at different times. The team decided to support the Indigenous academic in her effort to write a paper on the topic taking an interdisciplinary viewpoint. The Indigenous academic undertook the major writing of the paper, with contributions from other members of the team. The paper discussed the difficulty of using the law in cases where there were competing views and cultural complexities.

Whilst the groups' first paper was rejected a second paper again led by the Indigenous academic (Loban et al, 2012) which took a global approach to the topic was accepted for publication and was chosen as one of a select number of papers for publication in a 20 year anniversary edition of the Mabo Decision by the Indigenous Law Bulletin printed in September / October 2012.

\section{Reflections of the team}

Perspectives are derived from the lived experience. Rigney (1999) discussed the value of the lived experience in the context of Indigenous research in articulating Indigenist research methodologies. This paper draws on the lived experiences of the team members in drafting, crafting and submitting a paper for publication. Similar reflections have occurred with a team of Indigenous and non-Indigenous academics and students in mathematics (Matthews et al, 2005). However, no work was found that captured the reflections of teams comprised of both Indigenous and non-Indigenous academics and different disciplines.

In reflecting on the publication-writing process the team sought to hone in on matters of sensitivity and whether individuals experienced a 'lack of sensitivity' during the process. Sensitivity is argued in Manathaya (2009, p. 169) as an important aspect of intercultural collaboration endeavours.

\section{At the start}

The reflections from the academic with a commercial fishing background illustrated the fact that the topic itself, commercial fisheries in the Torres Strait, was and continues to be quite literally a contact zone with each side meeting at the borders and engaging in physical conflict at border crossings. However, rather than being a site of conflict, conversations about the issue between team members fostered the development of social capital, understanding and appreciation. Indeed it was building social capital across cultural bounds - Indigenous and non-Indigenous. One member reflected:

Being involved in the commercial fishing industry, I had always been aware of the controversy that this particular case had caused amongst the commercial fishers. I had only heard one side of the story and was interested in the other side. Heron and I used to discuss the case with each other over coffee and I was struck with the difference in viewpoints of the protagonists from the case in question. Our discussion provided us both with differing perspectives and highlighted to me some of the similarities 
between the goals of the protagonists and the differing view of what was considered to be ethical behaviour. Both the western and indigenous people sought to provide for families and maintain a life style they perceived as part of their inheritance.

Another member observed:

... it soon became evident that the topic had many dimensions to which each of us individually and collectively could contribute in a fruitful and meaningful way. In this way, the topic metamorphosed from a discussion around a topic which was of relevance to the region but had not meaning for me, to one which carried underlying concerns that were pertinent to the very things which I as a scholar was very much interested in. At this point I also realised that while I didn't know much about fisheries in the Torres Strait, I was keen to learn more about the topic and the people it concerned.

Along similar lines another member felt:

Prior to my acquaintance with this interdisciplinary topic my understanding of indigenous culture in general and indigenous fishery (traditional and commercial) in specific was basic and immature.

\section{Through the middle}

Interestingly, from the point of view of all members, both Indigenous and non-Indigenous, there appeared to be little discomfort in the contact zone or at the borders. This sits in direct contrast with the reflections of Somerville and Perkins (2003). This fact raises more questions than answers.

This may be due to the values of the individual members themselves and the sensitivity to the intercultural aspect of the team and the topic. One participant reflected:

In my view contemporary life we live in today is made by history and cultural diversification experienced in societies all around the world. Each and every one of these cultures has their own unique identity, economy, religion, and territorial claims.

Another commented:

My philosophy had always been that a person is to be valued for whom they are and that their cultural background is a rich tapestry that is intrinsically them, and not something that they should be ostracised for.

\section{In the end}

Reflections at the end of the process revealed the value of intercultural research collaborations in effecting cultural exchange and developing knowledge beyond the limits of one's own cultural experience and discipline. Difference was seen as contributing to the future thinking of individual team members in the reach of the team and potentially in their own research.

As I researched to formulate my contribution, I began to realise the extent of the topic as it related to Indigenous people in other communities, and the complexity of the 
associated issues. In this way, my perception of the topic became one of awe and unravelling curiosity as to how the issues could be reconciled. I remember thinking that the team could contribute in a positive way to "fair and equitable outcomes for all”.

At the beginning of this journey, however, I was not so aware the effect that culture had on our own values and reactions to differing circumstances, although I was open to new viewpoints. I have found that the exploration of this topic has enriched my understanding of non-western people's culture and beliefs and made me more aware .... This has then led me to a greater understanding still and now informs my work in this area.

\section{Discussion and Conclusion}

The limitations of this reflection are acknowledged. Not all people who have prior relationships can work together and people who do not have prior relationships can work together. At a baseline, prior relationships bring people together in research collaboration. However, it is the social capital that exists in the team that promotes success. Even then, it is the sensitivity, values and trust that is key.

In identifying the success factors of this team that other teams or individuals seeking to create teams can use to develop research collaborations across discipline and cultural bounds. There needs to be a strong foundation. A foundation of social capital. Out of that social capital there must be sensitivity, trust and valuing of difference. A lesson for the authors - the team must continue to be nourished. Social capital is relational and as such the relationships between the team members, Indigenous and non-Indigenous, must be maintained to in order keep the strength of the team (and its research).

\section{Works Cited}

\section{Legal Case}

R v Nona and Gesa, District Court of Queensland, Cairns, 29 January 2001 Unreported. Web. $18^{\text {th }}$ July 2011.

\section{Books and Chapters}

Burt, R. S. Structural holes: the social structure of competition. Cambridge; Harvard University Press. 1992. Eprint. 6 ${ }^{\text {th }}$ January 2012.

Bourdieu, P. "The forms of capital”. Handbook of theory and research for the sociology of education. Ed. J. G. Richardson. New York, Greenwood, 1986, 241-258. Web. $16^{\text {th }}$ March 2010

Strober, M. H. Interdisciplinary Conversations: Challenging Habits of Thought. Stanford; Stanford University Press. 2011. Eprint. 6 ${ }^{\text {th }}$ January 2012 
Wenger, E., R. McDermott and W. M. Snyder, Cultivating Communities of Practice: a guide to managing knowledge. Boston; Harvard Business School Press. 2002. Eprint. $7^{\text {th }}$ January 2012

\section{Journal Articles}

Baker, W. "Market networks and corporate behaviour". American Journal of Sociology 96 (1990): 589-625. Web. 18 $8^{\text {th }}$ July 2010.

Bordons, M., M. A. Zulueta, F. Romero, and S. Barrigon. "Measuring Interdisciplinary Collaboration within a University: The effects of the interdisciplinary research programme". Scientometrics 46.3 (1999): 383-398. Web. 14 ${ }^{\text {th }}$ December 2011

English, A. E. "Snatching the Catch or Asserting Native Title Ownership? Native Title, Queensland's Criminal Law and Commercial Fishing” Native Title News, 5.6 (2001): 99-104. Web. 23 ${ }^{\text {rd }}$ July 2011.

Fattore, T., Turnbull, N. and S. Wilson. “'More Community!’ Does the Social Capital Hypothesis Offer Hope for Untrusting Societies?” The Drawing Board: An Australian Review of Public Affairs 3.3 (2003): 165-179.

Foley, D. and A. J. O’Connor. "Social Capital and the Networking Practices of Indigenous Entrepreneurs”. Journal of Small Business Management 51.2 (2013): 276-296.

Haythornthwaite, C. "Learning and Knowledge Networks in Interdisciplinary Collaborations". Journal of the American Society for Information Science and Technology 57(8) (2006): 1079-1092. Web 12 ${ }^{\text {th }}$ December 2011.

Loban, H., Ciccotosto, S., Chaiechi, T., Pryce, J. and J. Hamilton. "Torres Strait Fisheries in a Global Context”. Indigenous Law Bulletin 8.2 (2012): 20-23.

Manathunga, C. "Research as an Intercultural 'Contact Zone””. Discourse: Studies in the Cultural Politics of Education 30.2 (2009): 165-177.

Matthews, C., Watego, L., Cooper, T. and A. Baturo. “Does Mathematics Education in Australia Devalue Indigenous Culture?: Indigenous Perspectives and Non-Indigenous Reflections" In Clarkson, P. et al., Proceedings of $28^{\text {th }}$ Conference of the Mathematics Education Research Group of Australasia 2 (2005): 513-520.

Morrissey, M. "Community, Social Capital and Indigenous Health in the Northern Territory”. Ethnicity and Health 11.3 (2006): 229-246.

Nahapiet, J., and S. Ghoshal. "Social Capital, Intellectual Capital and the Organizational Advantage”. Academy of Management Review 23.2 (1998): 242-266. Web. $20^{\text {th }}$ July 2010.

Naryan, D. and M. Cassidy. “A Dimensional Approach to measuring Social capital: Development and Validation of a Social Capital Inventory”. Current Sociology 59.2 (2001):59-102. 
Palmer, C. L. and L. J. Neumann. "The Information Work of Interdisciplinary Humanities Scholars: Exploration and translation”. The Library Quarterly 72.1 (2002): 85-117. Web. $12^{\text {th }}$ December 2011

Rigney, L.I. "Internationalisation of an Indigenous Anticolonial Cultural Critique of Research Methodologies: A Guide to Indigenist Research Methodology and its Principles”. Emergent Ideas in Native American Studies 14.2 (1999): 109-121.

Shaw, S. "The Soul of the Fisher". Paper presented at The Annual Conference of The Australian Sociological Association, 2 -5 December 2008, Melbourne Victoria. Web. 27 ${ }^{\text {th }}$ July 2011

Somerville, M. and Perkins, T. "Border Work in the Contact Zone: Thinking Indigenous/Non-Indigenous Collaboration Spatially”. Journal of Intercultural Studies 24.3 (2003): 253-266.

News Reports

Smith. A., "Rock Lobster Fishers Show Frustrations”. Torres News Edition 1070 (2013): 1-3. 